nr-AxSpA was made based upon the presence inflammatory low-back pain, human leukocyte antigen B27 positivity, and presence of sacroiliitis only in MRI. SLE was diagnosed with butterfly-shaped rash on her cheeks, inflammatory arthritis, photosensitivity, erythema involving dorsal inter-joint area of hand fingers, alopecia together with antinuclear antibody (ANA) and anti-dsDNA positivity, low serum complement levels, leucopenia and thrombocytopenia. Additional presence of sicca symptoms, low Schirmer I test, anti SSA/Ro and anti$\mathrm{SSB} / \mathrm{La}$ positivity, supported by positive labial salivary gland biopsy led to the diagnosis of SjS.

Results Furthermore, this patient also had miscarriage at 16th week and cerebral vascular disease at 33 years. Besides, IgG and IgM anticardiolipin antibodies were found to be positive twice. Therefore, she was also diagnosed as secondary APS. She fulfilled the relevant criteria for AxSpA, SLE, SjS and APS.

Conclusions To our knowledge, this is the first case report showing the association of these four diseases, with different genetic, etiopathogenetic and clinical systemic inflammatory diseases.

Funding Source(s): No

\section{THE DISCORDANCE BETWEEN PATIENT AND PHYSICIAN PERCEPTION OF THE DISEASE: THE PARADIGM OF SLE}

${ }^{1}$ Elena Elefante ${ }^{*},{ }^{2}$ Chiara Tani, ${ }^{3}$ Francesco Ferro, ${ }^{2}$ Chiara Stagnaro, ${ }^{3}$ Alice Parma, ${ }^{2}$ Linda Carli, ${ }^{2}$ Viola Signorini, ${ }^{4}$ Marta Mosca. ${ }^{1}$ University of Siena, Siena, Italy; ${ }^{2}$ Rheumatology Unit, Department of Clinical and Experimental Medicine, University of Pisa, Pisa, Italy; ${ }^{3}$ University of Pisa; ${ }^{4}$ Director Rheumatology Unit, Associate Professor in Rheumatology, University of Pisa

\subsection{6/lupus-2019-Ism.270}

Background Background: a discordance exists between patient and physician perspective in the evaluation of SLE and it may negatively impact on patient care. Our purpose was to compare patient and physician evaluation of the disease in a monocentric cohort of SLE patients, analyzing factors that influence patient perception.

Methods Methods: this is a cross-sectional study that enrolls adult patients with a diagnosis of SLE (ACR 1997 criteria). For each patient, demographics, comorbidities, treatment history, clinical and laboratory data were collected. Disease activity was evaluated with the SELENA-SLEDAI score and organ damage with the SLICC/DI. At enrollment each patient completed the following PROs: SF-36, FACIT-F, LIT, SLAQ and BILD. The Spearman test has been used for linear correlation between continuous data.

Results Results: we included 223 adult SLE patients $(97,24 \%$ Caucasian, 91,93\% female, mean age 44,9413,17 years, median disease duration 13 years). Median SLEDAI at enrollment was 2 (IQR $0-4$ ); 18,22\% of patients had SLEDAI >4; $49,33 \%$ had SLICC/DI $>0.11,8 \%$ of the cohort had a concomitant fibromyalgia. At enrollment, the most frequent active disease manifestations were articular (36/223) and hematological (33/223), while only 15 patients had active renal involvement.

The median score of the SLAQ questionnaire was 11 (IQR 6-16). No correlation was found between patients self-evaluation of the disease and the physicians assessment: SLAQ and SLEDAI scores were not significantly correlated.

\begin{tabular}{|c|c|}
\hline & SLAQ \\
\hline $\mathrm{PF}$ & $\begin{array}{l}r=-0,56 \\
p<0,001\end{array}$ \\
\hline $\mathrm{RP}$ & $\begin{array}{l}r=-0,58 \\
p<0,001\end{array}$ \\
\hline $\mathrm{BP}$ & $\begin{array}{l}\boldsymbol{r}=\mathbf{- 0 , 6 7} \\
p<0,001\end{array}$ \\
\hline $\mathrm{GH}$ & $\begin{array}{l}r=-0,50 \\
p<0,001\end{array}$ \\
\hline $\mathrm{VT}$ & $\begin{array}{l}\boldsymbol{r}=\mathbf{- 0 , 6 5} \\
p<0,001\end{array}$ \\
\hline $\mathrm{SF}$ & $\begin{array}{l}\boldsymbol{r}=\mathbf{- 0 , 6 4} \\
p<0,001\end{array}$ \\
\hline $\mathrm{RE}$ & $\begin{array}{l}r=-0,55 \\
p<0,001\end{array}$ \\
\hline $\mathrm{MH}$ & $\begin{array}{l}r=-0,57 \\
p<0,001\end{array}$ \\
\hline LIT & $\begin{array}{c}\boldsymbol{r}=\mathbf{0 , 7 4} \\
p<0,001\end{array}$ \\
\hline FACIT & $\begin{array}{l}r=-\mathbf{0 , 7 2} \\
p<0,001\end{array}$ \\
\hline
\end{tabular}

Among active disease manifestations, only arthritis $(p=0,03)$ and skin involvement $(p=0,04)$ resulted significantly associated with higher SLAQ scores. Moreover, the SLAQ score resulted significantly influenced by fibromyalgia $(\mathrm{p}<0,001)$ : patients with fibromyalgia seems to overestimate SLE disease activity. Finally, while SLEDAI didnt show any correlation with PROs on HRQoL, higher SLAQ scores were strongly associated with a worst patient perception of QoL, fatigue and SLE impact, as expressed by SF-36, FACIT-F and LIT (table 1).

Conclusions Conclusion: differently from the physicians assessment, SLE patients evaluation of their disease is influenced by milder manifestations but with a heavy impact on daily functioning, like arthritis and fibromyalgia. Patients self-evaluation has a strong impact on their perception of health status and disease burden. The integration of patient-driven data to the traditional clinical evaluation may improve the management of SLE patients. 
Abstract 271 Table 1 Maternal and fetal characteristics of the $19 \mathrm{NL}$ cases

\begin{tabular}{|c|c|c|c|c|c|}
\hline $\begin{array}{l}\mathrm{NL} \\
\text { case }\end{array}$ & $\begin{array}{l}\text { Maternal ethnic } \\
\text { group* }\end{array}$ & $\begin{array}{c}\text { Maternal } \\
\text { autoimmune } \\
\text { disease }\end{array}$ & $\begin{array}{l}\text { Number of } \\
\text { pregnancies }\end{array}$ & $\begin{array}{c}\text { Cardiac } \\
\text { involvement }\end{array}$ & Other involvement \\
\hline 1 & Amerindian & None & 1 & AV block type III & \\
\hline 2 & ND & pSS & 1 & AV block type III & \\
\hline 3 & ND & pSS & 3 & NO & Cutaneous \\
\hline 4 & ND & None & 1 & $\mathrm{NO}$ & Cutaneous/hematologic/liver \\
\hline 5 & White & pSS & 1 & AV block type III & \\
\hline 6 & White & SLE & 1 & NO & Cutaneous \\
\hline 7 & White & pSS & 2 & AV block type I & \\
\hline 8 & White & SLE & 1 & AV block type III & \\
\hline 9 & White & SLE & 1 & AV block type III & \\
\hline 10 & Mestizo & pSS & 1 & NO & Cutaneous/hematologic \\
\hline 11 & Mestizo & None & 1 & AV block type III & \\
\hline 12 & White & SLE & 1 & AV block type III & \\
\hline 13 & White & SLE & 1 & $\mathrm{NO}$ & Cutaneous \\
\hline 14 & ND & SLE & 1 & NO & Cutaneous \\
\hline 15 & White & None & 1 & AV block type III & \\
\hline 16 & White & None & 1 & AV block type III & \\
\hline 17 & Mestizo & SLE & 2 & AV block type III & \\
\hline 18 & White & RA & 2 & NO & Cutaneous \\
\hline 19 & ND & SLE & 2 & AV block type III & \\
\hline
\end{tabular}

*: according GLADEL ethnic groups. NL: neonatal lupus; ND: not defined; AV, atrioventricular; SLE:, systemic lupus erythematosus; pSS: primary Sjögren syndrome; RA: Rheumatoid Arthritis.

Funding Source(s): Founding: INTEGRATE project (European Commission, 3rd Health Program, Proposal ID 769736)

\section{FREQUENCY OF NEONATAL LUPUS IN REFERENCE CENTERS IN THE MANAGEMENT OF PREGNANCY AND AUTOIMMUNE DISEASES}

${ }^{1}$ Carla Maldini* ${ }^{*}$ 'Cintia Otaduy, ${ }^{2}$ Florencia Beatriz Mollerach, ${ }^{2}$ Marina Scolnik, ${ }^{3}$ Belen Maria Virasoro, ${ }^{3}$ Cecilia Pisoni, ${ }^{4}$ Mercedes Croce, ${ }^{4}$ Maria Hu, ${ }^{5}$ Fabiola Natalia Camargo Serrudo, ${ }^{6}$ Diana Dubinsky, ${ }^{7}$ María de la Paz Leon, ${ }^{7}$ Veronica Bellomio, ${ }^{8}$ Daniela Flores Rengifo, ${ }^{8}$ Eduardo Kerzberg, ${ }^{9}$ Fernanda Guzzanti, ${ }^{9}$ Emma E Civit, ${ }^{10}$ Ana Bertoli, ${ }^{10}$ Maria Jose Lopez Perez, ${ }^{11}$ Maximiliano Machado Escobar, ${ }^{12}$ Veronica Savio, ${ }^{12}$ Alejandra Babini, ${ }^{13}$ Cecilia Alvarez, ${ }^{13}$ Verónica Saurit, ${ }^{14}$ Rosa Serrano Morales, ${ }^{15}$ Cruz Lascano, ${ }^{16}$ María Constanza Danielsen, ${ }^{17}$ Mayra Etcheverry, ${ }^{17}$ Adrian Estevez, ${ }^{18}$ Marina Werner, ${ }^{18}$ Laura Onetti, ${ }^{1}$ Paula Alba, ${ }^{19}$ Carla Gobbi. ${ }^{1}$ Cátedra de Semiología UHMI 3 Hospital Córdoba FCM Universidad Nacional de Córdoba, Córdoba, Argentina; ${ }^{2}$ Hospital Italiano de Buenos Aires, Argentina; ${ }^{3}$ Centro de Educación Médica e Investigaciones Clínicas Norberto Quirno (CEMIC), Buenos Aires, Argentina; ${ }^{4}$ Hospital Penna, Buenos Aires, Argentina; ${ }^{5}$ Rheumatology Division, Sanatorio Guemes; ${ }^{6}$ Sanatorio Guemes; ${ }^{7}$ Hospital Padilla, Tucumán, Argentina; ${ }^{8}$ Hospital J. M. Ramos Mejía, Buenos Aires, Argentina; ${ }^{9}$ Hospital El Carmen, Mendoza, Argentina; ${ }^{10}$ Clínica Universitaria Reina Fabiola, Universidad Católica de Córdoba, Córdoba. Argentina; ${ }^{11}$ Instituto de Maternidad y Ginecologia Nuestra Sra de las Mercedes, Tucuman, Argentina; ${ }^{12}$ Hospital Italiano, Córdoba, Argentina; ${ }^{13}$ Servicio de Reumatología, Hospital Privado Universitario de Córdoba, Córdoba, Argentina; ${ }^{14}$ Centro Regional de Enfermedades Autoinmunes y Reumáticas (GO(REAR)/Maternidad Oroño, Rosario, Argentina; ${ }^{15}$ Hospital San Roque, San Salvador de Jujuy, Argentina; ${ }^{16}$ Clínica del Pilar, Santiago del Estero, Argentina; ${ }^{17}$ Hospital de Alta Complejidad El Cruce, Buenos Aires, Argentina; ${ }^{18}$ Hospital Nacional de Clínicas, Córdoba, Argentina; ${ }^{19}$ Universidad Nacional de Córdoba

10.1136/lupus-2019-|sm.271

Background Neonatal lupus (NL) is a disease in children of mothers who have specific anti-Ro/La IgG autoantibodies by passive transplacental transfer. $\mathrm{LN}$ is characterized by skin and cardiac involvement, as well as cytopenias, hepatic or neurological manifestations. NL can be diagnosed intra-uterus or in neonatal period, being self-limiting in several months or be irreversible. Congenital heart block $(\mathrm{CHB})$ in a structurally normal heart, is perhaps the most serious manifestation with an estimated mortality rate of around 19\%. Objetives: to estimate the frequency of NL in children of mothers with anti$\mathrm{Ro} / \mathrm{La}$ in reference centers in the management of pregnancy and autoimmune diseases in Argentina, and to describe maternal and children features.

Methods A descriptive multicenter study was conducted in reference centers in the management of autoimmune diseases and pregnancy in Argentina. Inclusion criteria were the presence of positive maternal serology anti-Ro/La and at least one pregnancy. Demographic and maternal-fetal clinical data were obtained from the clinical histories and each center completed a data collection form created for this study. We defined a NL case (born or not) who presented, pre and/or postpartum, characteristic skin lesions, cytopenias, cardiac involvement (CHB, endocardial fibroelastosis and dilated cardiomyopathy), hepatic or neurological manifestations. Ethnicity was classified using GLADEL groups. NL frequency was calculated dividing the number NL cases by the number of mothers with positive anti-Ro/La serology.

Results 18 reference centers in the management of autoimmune diseases and pregnancy participated in this study in 7 different geographic areas of Argentina (6 of Buenos Aires, 6 of Cordoba, 1 of Jujuy, 1 of Mendoza, 1 of Santa Fe, 1 of Santiago del Estero and 2 of Tucuman). 193 mothers with positive anti-Ro/La serology were included with 364 pregnancies. 19 cases NL cases were reported (10 diagnosed during 